\title{
Developing Table Tennis Strokes Skill through Learning Method, Feedback and Agility
}

\author{
Jonni Siahaan ${ }^{1}$ \\ ${ }^{1}$ Universitas Cenderawasih, Indonesia \\ Correspondence: Jonni Siahaan, Universitas Cenderawasih, Kampus UNCEN Waena, Jl. Camp Wolker, Jayapura, \\ Indonesia. E-mail: jonni.siahaan@gmail.com
}

Received: January 16, 2014

Accepted: February 20, 2014 Online Published: February 28, 2014

doi:10.5539/ass.v10n5p63

URL: http://dx.doi.org/10.5539/ass.v10n5p63

\begin{abstract}
This paper presents a discussion on the learning method, feedback and agility needed in the process of developing table tennis strokes skills. The learning method used is the random learning method, which is categorized into regular and irregular. The regular method is developing the table tennis service, drive, smash and lob sequentially and the irregular method is freely choosing the strokes. The feedback, divided into direct feedback through demonstration and direct feedback using the words right or wrong. The agility is categorized into poor, average and good agility. This article gives an overview of the table tennis strokes skill development through the random learning method, using direct feedback and agility. Data were analyzed using ANOVA Scheffe's test, with the level of significant is set at $\alpha<0.05$, and is concluded as follow: 1 ) the regular random learning method (RLM-r) is significantly different than the irregular random learning method (RLM-ir) 2) the direct feedback using demonstration (DF-d) is significantly different than the direct feedback using right or wrong (DF-rf) 3) the good agility (H-a) is significantly different than average agility (M-a) and poor agility (L-a) 4) there is an interaction between random learning method (RLM), and direct feedback (DF) with agility 5) there is an interaction between random learning method (RLM) with agility 6) there is an interaction between direct feedback (DF) with agility 7) there is an interaction between random learning method (RLM), direct feedback (DF) with agility 8) the combination between regular random learning method (RLM-r) with direct feedback through demonstration (DF-d) with good agility (H-a) is significantly different and is better than the combination of regular random learning method (RLM-r) with direct feedback using right or wrong (DF-rf), with high agility (H-a) 9) the combination between regular random learning method (RLM-r) with direct feedback using demonstration (DF-d) with poor agility (L-a) is not significantly different than the combination of regular random learning method (RLM-r) with direct feedback using right or wrong(DF-rf), with poor agility (L-a) 10) the combination between irregular random learning method (RLM-ir) with direct feedback using demonstration (DF-d) with good agility ( $\mathrm{H}-\mathrm{a})$ is not significantly different than the combination of irregular random learning method (RLM-r), direct feedback using right or wrong (DF-rf), with good agility (H-a) 11) the combination between irregular random learning method (RLM-ir), direct feedback using demonstration (DF-d), with poor agility (L-a) is not significantly different than the combination between irregular random learning method (RLM-r), direct feedback using right or wrong (DF-rf), with poor agility (L-a).
\end{abstract}

Keywords: learning method, feedback, agility, table tennis skills

\section{Introduction}

Davis (1997) states that through the learning process, changes in performance will relatively be permanent. The changes in performance is related to optimal learning experiences of the students, and also related to increases in psychomotor skills. 


\section{Successful Performance}

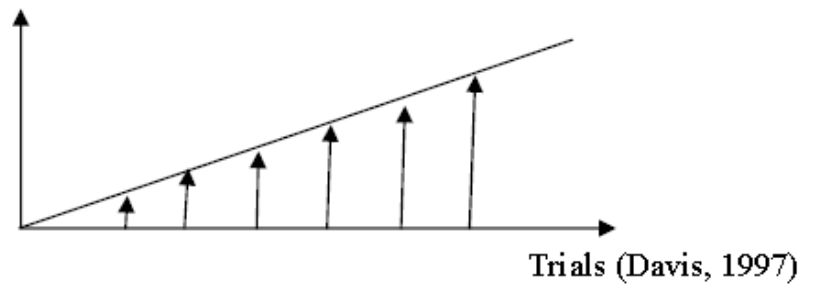

Figure 1. Relationship between successful performance and trials

The diagram above explains that increases in learning are a result of gradual attainment of performance or psychomotor skills with learning experiences. This theory is deemed applicable in developing table tennis strokes skill among students.

The teaching of table tennis strokes skills still need attention on the best learning method to be used, the learning stages that would be reached, the improvements in the learning result, and the parameter used to measure the learning result.

The parameter used to develop the sport skills according to Magil (2004) should measure the action or task, and the quality of performance. The performance should be measure through the action goal, the reflex performance, and the goal direction. The quality of performance is measured through the productivity of performance and the consistency of performance.

Table tennis strokes skills are varied and Simpson (2007) stated that to be the best, players must know all the table tennis skills. The strategy is to develop the variety of table tennis strokes skill. Hamzah, (2007) stated that learning method is a strategy to develop many skills While Magill, (2004) states that learning method is a way to change a skill which relatively will be permanent. One of the learning method that could be used to develop the table tennis strokes skill is random learning methods (William, 1994).

Hodges (2000) states that there are actually four basic strokes skill in table tennis, but nowadays, the strokes were introduced in table tennis. In this research, the students learn four table tennis strokes skill consecutively termed as regular random learning method and irregular learning random method teaches the same four strokes not in a sequential way.

While playing table tennis, students make many mistakes, therefore they need to reduce and ultimately eliminate the mistakes. Schmidt (1991) and Drowatzky (1981) states that the mistakes can be eliminated through feedback. Schmidt (1991) states that feedback can be immediate or direct. Magil (2004) state that feedback can be given either verbally or by demonstration. Giving feedback through demonstrate will correct the the skill by doing the best strokes for that particular skill, while verbal feedback uses the word right or wrong to correct the skill. If the students make mistakes, feedback should be given immediately so that students can immediately correct their mistakes.

Physical conditioning is also important in order to develop table tennis strokes skill. One of the physical conditioning domain that a table tennis player need is agility, especially to develop footwork skill. Preiss (1992) stated that good footwork skill prepares the table tennis player to always be in ready position to receive or return the ball. Jackson and Baumgatner (1982) and Verducci (1980) states that agility is the ability of part and the whole body to move quickly. Davis (1997) and Kirkendal (1980) states that agility is categorize into five category: excellent, good, average, fair, and poor. However for this research, agility is categorize into three namely poor, average and good.

\section{Methodology}

This is an experimental study using $2 \times 2 \times 3$ factorial design (Kerlinger, 2000). A sample of 120 students were chosen using multistage purposive sampling (Gulo, 2003) were selected for this study. The independent variables in this study is divided into two, active variable and attributive variable. Active independent variables are regular learning method and irregular learning method, and direct feedback which is also divided into two namely direct feedback through demonstration (DF-d), and direct feedback using right or wrong cue words (DF-rf). Attributive independent variable is agility, which is categorized into good agility $(\mathrm{H}-\mathrm{a})$, average agility (M-a) and poor agility (L-a). 
Active independent variable can be manipulated (Kerlinger, 2000) while attributive independent variable cannot be manipulated (Nazir,1988), but must be counted (Azwar,1986). There were seven variables in this study namely regular random learning method, irregular random learning method, right or wrong direct feedback, demonstration direct feedback, agility, and table tennis stroke skill test created by Bambang (2003).

The reliability for agility test is average $(\mathrm{r}=6.658)$ (Kirkendal, 1980). The table tennis strokes skills test created by Bambang (2003) consist of four skills test which is service, drive, chop and lob, all having a reliability coefficient of more than 0.90 .

\section{Result and Discussions}

The descriptive statistic for all the variables is shown in Table 1 .

Table 1. Descriptive statistics for variables studied

\begin{tabular}{|c|c|c|c|c|c|}
\hline Random Learning Method & Directly Feedback & Agility & Mean & Std Deviation & $\mathrm{N}$ \\
\hline \multirow[t]{12}{*}{ Regular } & \multirow[t]{4}{*}{ Directly Feedback right/wrong } & High & 186.1500 & 1.63384 & 10 \\
\hline & & Medium & 164.6500 & .62583 & 10 \\
\hline & & Low & 144.2500 & 2.2 .60608 & 10 \\
\hline & & Total & 165.0167 & 17.48767 & 30 \\
\hline & \multirow[t]{4}{*}{ Directly Feedback demonstrate } & High & 219.7500 & 3.59977 & 10 \\
\hline & & Medium & 183.0800 & 1.66119 & 10 \\
\hline & & Low & 160.9000 & 2.02485 & 10 \\
\hline & & Total & 187.9100 & 24.80608 & 30 \\
\hline & \multirow[t]{4}{*}{ Overall } & High & 202.9500 & 17.44985 & 20 \\
\hline & & Medium & 173.8650 & 9.53300 & 20 \\
\hline & & Low & 152.5750 & 8.83813 & 20 \\
\hline & & Total & 176.4633 & 24.20786 & 60 \\
\hline \multirow[t]{12}{*}{ Irregular } & \multirow[t]{4}{*}{ Directly Feedback right/wrong } & High & 174.1500 & 1.54650 & 10 \\
\hline & & Medium & 155.3500 & 1.22588 & 10 \\
\hline & & Low & 134.0500 & 2.55441 & 10 \\
\hline & & Total & 154.5167 & 16.75816 & 30 \\
\hline & \multirow[t]{4}{*}{ Directly Feedback demonstrate } & High & 184.1000 & 1.44914 & 10 \\
\hline & & Medium & 163.000 & 1.85592 & 10 \\
\hline & & Low & 144.9000 & 1.30809 & 10 \\
\hline & & Total & 164.0000 & 16.36475 & 30 \\
\hline & \multirow{4}{*}{ Overall } & High & 179.1250 & 5.30857 & 20 \\
\hline & & Medium & 159.1750 & 4.21237 & 20 \\
\hline & & Low & 139.4750 & 5.90631 & 20 \\
\hline & & Total & 159.2583 & 17.10226 & 60 \\
\hline \multirow[t]{12}{*}{ Total } & \multirow[t]{4}{*}{ Directly Feedback right/wrong } & High & 180.1500 & 6.34761 & 10 \\
\hline & & Medium & 160.0000 & 4.86394 & 10 \\
\hline & & Low & 139.1500 & 5.80404 & 10 \\
\hline & & Total & 159.7667 & 17.78722 & 30 \\
\hline & \multirow[t]{4}{*}{ Directly Feedback demonstrate } & High & 201.9250 & 18.48205 & 10 \\
\hline & & Medium & 173.0406 & 10.44249 & 10 \\
\hline & & Low & 152.9000 & 8.37383 & 10 \\
\hline & & Total & 175.9550 & 24.0704 & 30 \\
\hline & \multirow[t]{4}{*}{ Overall } & High & 191.0375 & 17.53911 & 20 \\
\hline & & Medium & 166.5200 & 10.40437 & 20 \\
\hline & & Low & 146.0250 & 9.95242 & 20 \\
\hline & & Total & 167.8608 & 22.5873 & 60 \\
\hline
\end{tabular}


Further analysis using ANOVA were conducted and is shown in Table 2.

Table 2. Results of ANOVA

\begin{tabular}{llllll}
\hline Source & Type III Sum of Squares & $\mathrm{df}$ & Mean Square & $\mathrm{F}$ & Sig. \\
\hline Corrected Model & $60286.215 \mathrm{a}$ & 11 & 5480.565 & 1389.077 & .000 \\
Intercept & 3381271.124 & 1 & 3381271.124 & 857000.4 & .000 \\
Random Learning Method (RLM) & 8880.361 & 1 & 8880.361 & 2250.773 & .000 \\
Direct Feedback (DF) & 7861.864 & 1 & 7861.864 & 1992.629 & .000 \\
Agility (a) & 40630.373 & 2 & 20315.187 & 5148.987 & .000 \\
RLM*DF & 1348.711 & 1 & 1348.711 & 341.838 & .000 \\
RLM*a & 670.006 & 2 & 335.003 & 84.908 & .000 \\
DF*a & 470.683 & 2 & 235.342 & 59.649 & .000 \\
RLM*DF*a & 424.217 & 2 & 212.108 & 53.760 & .000 \\
Error & 426.111 & 108 & 3.945 & & \\
Totality & 3441983.450 & 120 & & & \\
Corrected Total & 60712.326 & 119 & & & \\
\hline
\end{tabular}

\subsection{Table Tennis Strokes Skills of the Students}

Data analysis showed that random learning method has significant effect $(\mathrm{F}=2250.773, \mathrm{p}<0.05)$ on table tennis strokes skills of the students. Scheffe's post hoc test was further conducted and showed that regular random learning method (RLM-r) is significantly different than irregular random learning method (RLM-ir). This proves that the regular random learning method is significantly better for developing table tennis strokes skill. Descriptive statistic in Table 1, found total mean of RLM-r $=176.4633$ and RLM-ir $=159.2683$, and according to Kerlinger, (2000) the relationship between (RLM-r)*(RLM-ir), could be described, as below:

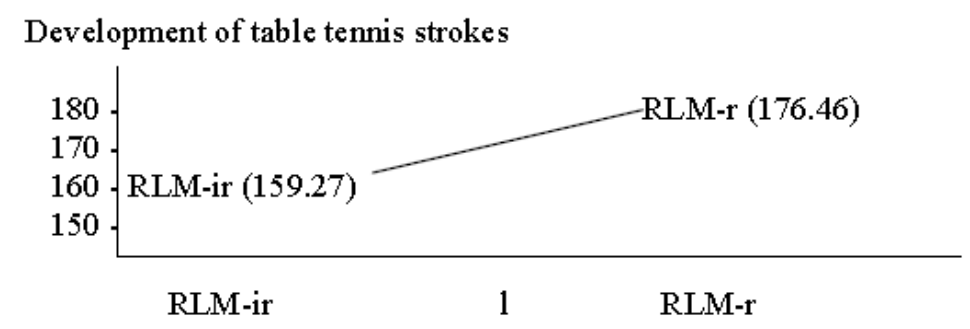

Figure 2. Relationship between two learning method in developing table tennis strokes skills

\subsection{Table Tennis Strokes Skill Development through Feedback}

Direct feedback has significant effect $(\mathrm{F}=1992.63, \mathrm{p}<0.05)$ on table tennis stroke development of the sample. Scheffe's post hoc test was further conducted and showed that direct feedback through demonstration (DF-d) is significantly different than direct feedback using right or wrong cue words (DF-rf). This proves that the direct feedback using demonstration is significantly better for developing table tennis strokes skill. Descriptive statistic found that the total mean of DF-d (175.9550) and DF-rf (159.7667), and according to Kerlinger, (2000) there is a relation between DF-d and DF-rf, as shown in Figure 3.

\section{The Development Table Tennis Strokes Skill}

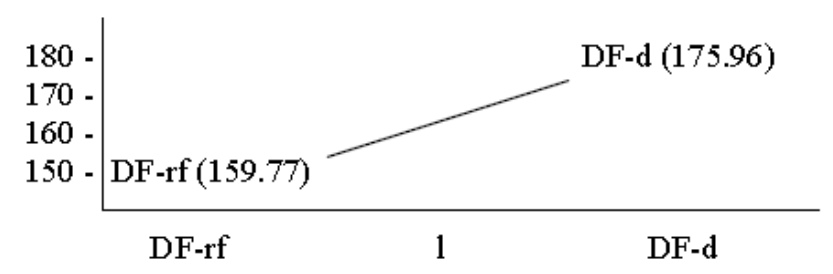

Figure 3. Relationship between two types of feedback in developing table tennis strokes skills 


\subsection{Development Table Tennis Strokes Skill through Agility}

Agility has significant effect $(\mathrm{F}=5148.99, \mathrm{p}<0.05)$ on table tennis stroke development of the sample. Scheffe's post hoc test was further conducted and showed that good agility $(\mathrm{H}-\mathrm{a})$ is significantly different than average agility (M-a) and poor agility (L-a). This proves that good agility is significantly better for developing table tennis strokes skill. Descriptive statistic found that the total mean of $\mathrm{H}-\mathrm{a}=191.0375, \mathrm{M}-\mathrm{a}=166.5200$ and $\mathrm{L}-\mathrm{a}=146.0250$, and according to Kerlinger, (2000) there is an interaction between $(\mathrm{H}-\mathrm{a})^{*}(\mathrm{M}-\mathrm{a})^{*}(\mathrm{~L}-\mathrm{a})$, as shown in Figure 4.

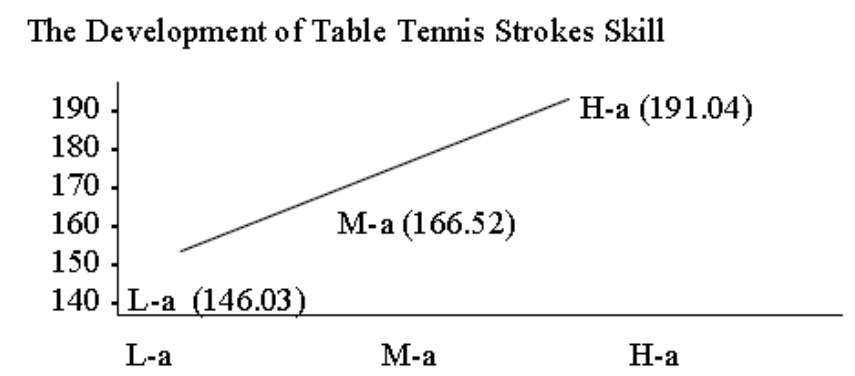

Figure 4. Relationship between level of agility in developing table tennis strokes skills

\subsection{Interaction Random Learning Method and Direct Feedback}

Data analysis showed that there is a significant interaction $(\mathrm{F}=341.84, \mathrm{p}<0.05)$ between random learning method (RLM) and direct feedback (DF) for developing of table tennis strokes skill. The interaction is shown in Figure 5 .

\section{The Development of Table Tennis Strokes Skill}

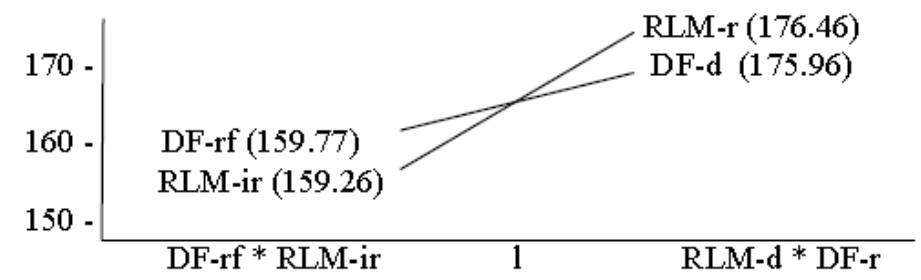

Figure 5. Interaction between random learning method and direct feedback

\subsection{Interaction between Random Learning Method and Agility}

Data analysis showed that there is a significant interaction $(\mathrm{F}=84.91, \mathrm{p}<0.05)$ between random learning method (RLM) and agility (a) for developing of table tennis strokes skill. The interaction is shown in Figure 6.

\section{The Development of Table tennis strokes skill}

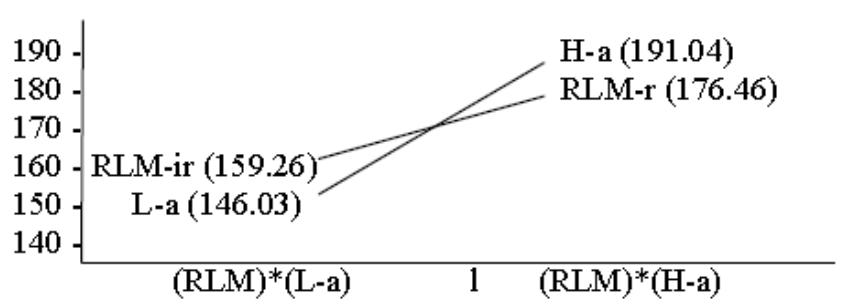

Figure 6. Interaction between random learning method and agility

\subsection{Interaction Direct Feedback and Agility}

Data analysis showed that there is a significant interaction $(\mathrm{F}=59.65, \mathrm{p}<0.05)$ between direct feedback $(\mathrm{DF})$ and agility (a) for developing of table tennis strokes skill. The interaction is shown in Figure 7. 


\section{The Development of Table Tennis Strokes Skill}

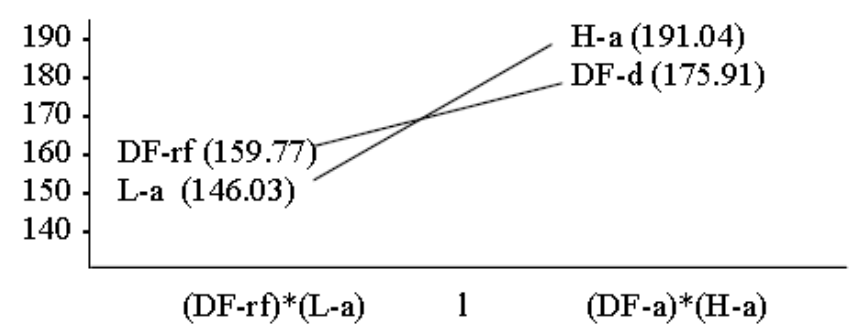

Figure 7. Interaction between direct feedback and agility

3.7 Interaction between Random of Learning Method (RLM), Direct Feedback (DF) with Agility (A) for Developing of Table Tennis Strokes Skill

Data analysis showed that there is a significant interaction $(\mathrm{F}=53.76, \mathrm{p}<0.05)$ between random learning method (RLM), direct feedback (DF) and agility (a) for developing of table tennis strokes skill. The interaction is shown in Figure 8.

\section{The Development of Table Tennis Strokes Skill}

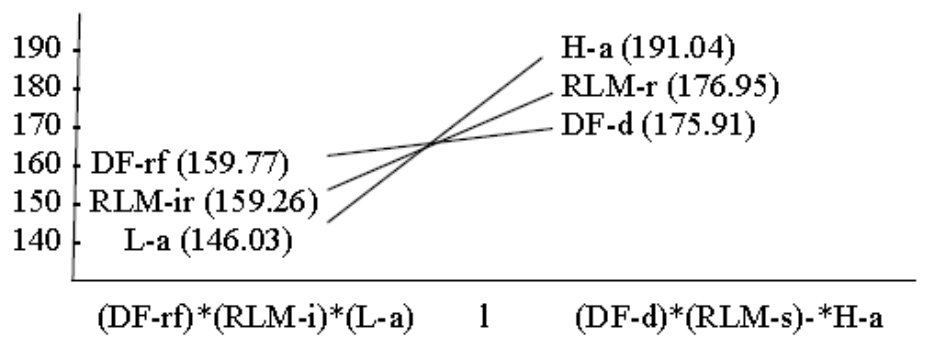

Figure 8. Interaction between random learning method, direct feedback and agility

a. The combination between regular random learning method (RLM-r), direct feedback using demonstration (DF-d) with good agility (H-a) and regular random learning method (RLM-r), direct feedback using right or wrong cue words (DF-rf) with good agility $(H-a)$ for developing of table tennis strokes skill.

Data analysis (Table 2) showed that the combination (RLM-r)*(DF-d)*(H-a) is significantly different $(\mathrm{F}=10.44$, $\mathrm{p}<0.05)$ than $(\mathrm{RLM}-\mathrm{r})^{*}(\mathrm{DF}-\mathrm{rf}) *(\mathrm{H}-\mathrm{a})$. This showed the combination between regular random learning method (RLM-r), direct feedback using demonstration (DF-d) with good agility (H-a) is significantly better (Scheffe's post hoc test $\mathrm{F}=1426.06, \mathrm{p}<0.05$ ) than the combination regular random learning method (RLM-r),direct feedback using right or wrong cue words (DF-rf), with good agility (H-a) for developing of table tennis strokes skill.

$b$. The combination between regular learning method (RLM), direct feedback using demonstration (DF-d) with poor agility (L-a) and regular random learning method (RLM), direct feedback using right or wrong cue words (DF-rf) with poor agility (L-a) for developing of table tennis strokes skill.

Data analysis (Table 2) showed that the combination (RLM-r*DF-d*L-a) is not significantly different $(\mathrm{F}=0.44$, $\mathrm{p}>0.05)$ than (RLM-r*DF-rf*L-a). This showed that there is no difference between the combination of regular random learning method (RLM-r), direct feedback using demonstration (DF-d) with poor agility (L-a) and the combination regular random learning method (RLM-r),direct feedback using right or wrong cue words (DF-rf), with poor agility (L-a) for developing of table tennis strokes skill.

c. Combination between irregular random learning method (RLM-ir) and direct feedback using demonstration (DF-d) with good agility (H-a) and irregular random learning method (RLM-ir) with direct feedback using right or wrong cue words (DF-rf) with good agility (H-a) for developing of table tennis strokes skill.

Data analysis (Table 2) showed that the combination (RLM-r*DF- $\left.\mathrm{d}^{*} \mathrm{H}-\mathrm{a}\right)$ is not significantly different $(\mathrm{F}=0.266$, $\mathrm{p}>0.05)$ than (RLM-r*DF-rf*H-a). This showed that there is no difference between the combination of regular random learning method (RLM-r), direct feedback using demonstration (DF-d) with good agility (H-a) and the 
combination regular random learning method (RLM-r),direct feedback using right or wrong cue words (DF-rf), with good agility $(\mathrm{H}-\mathrm{a})$ for developing of table tennis strokes skill.

$d$. The combination between irregular learning method (RLM), direct feedback using demonstration (DF-d) with poor agility (L-a) and irregular random learning method (RLM), direct feedback using right or wrong cue words (DF-rf) with poor agility (L-a) for developing of table tennis strokes skill.

Data analysis (Table 2 ) showed that the combination (RLM-ir*DF- $\left.\mathrm{d}^{*} \mathrm{~L}-\mathrm{a}\right)$ is not significantly different $(\mathrm{F}=2.18$, $\mathrm{p}>0.05)$ than (RLM-ir*DF-rf*L-a). This showed that there is no difference between the combination of regular random learning method (RLM-r), direct feedback using demonstration (DF-d) with poor agility (L-a) and the combination regular random learning method (RLM-r),direct feedback using right or wrong cue words (DF-rf), with poor agility (L-a) for developing of table tennis strokes skill.

\section{Implication and Conclusion}

The implications for this study are:

1) The regular random learning method could be used to acquiresport skills, especially sports which requires manipulative skills.

2) The direct feedback is effective to improve psychomotor.

3) The level of agility is a good indicator for success in sports skills development.

Therefore, to develop table tennis stroke skills, it can be concluded that:

1) Regular random learning method is significantly better than the irregular random of learning method.

2) Direct feedback through demonstration is significantly better than direct feedback using right/wrong cue words.

3) Having good agility is significantly better than average agility and poor agility

4) There is a significant interaction between random learning method with direct feedback for developing of table tennis strokes skill

5) There is a significant interaction between random learning method with agility for developing of table tennis strokes skill

6) There is a significant interaction between direct feedback with agility for developing of table tennis strokes skill

7) There is a significant interaction between random learning method, direct feedback with agility for developing of table tennis strokes skill

8) The combination between regular random learning method with direct feedback through demonstration with good agility is significantly better than regular random learning method, direct feedback using right/wrong cue words with good agility for developing of table tennis strokes skill

9) There is no difference between the combination of regular learning method, direct feedback through demonstration with poor agility and regular random learning method, direct feedback using right/wrong cue words with poor agility for developing of table tennis strokes skill.

10) There is no difference between the combination of irregular learning method, direct feedback through demonstration with high agility and irregular random learning method, direct feedback using right/wrong cue words with high agility for developing of table tennis strokes.

11) There is no difference between the combination of irregular learning method, direct feedback through demonstration with low agility and irregular random learning method, direct feedback using right/wrong cue words with low agility for developing of table tennis.

\section{References}

Bambang, K. (2003). Penyusunan Tes dan Norma Keterampilan Tenis Meja. Jurnal Ilmu Keolahragaan, Fortius, FIK UNJ, Vol 3, No.1 Maret 2003. Jakarta.

Davis, B. (1997). Physical Education and the Study of Sport. USA : Mosby International.

Drowatzky, J. N. (1981). Motor Learning, Principles and Practices. USA, Burgess Publishing Company.

Gulo, W. (2007). Metodologi Penelitian. Penerbit Gramedia Widiasarana Indonesia Jakarta.

Hamzah, U. (2007). Perencanaan Pembelajaran. Penerbit Bumi Aksara, Jakarta. 
Hodges, L. (2000). Step to Success, Tenis Meja. Tingkat Pemula, Penerbit Raja Grafindo Persada, Jakarta.

Irianto, A. (2004). Statistika, Konsep Dasar dan Aplikasinya. Penerbit Prenada Media Jakarta.

Jackson, A. S., \& Baumgatner, T. A. (1987). Measurement for Evaluation in Physical Education and Exercises Science. USA: Wm, C. Brown.

Kerlinger, F. N. (2000). Azas-azas Penelitian Behavioral. Penerbit Gadjah Mada University Press.

Kirkendal, D. R., Gruber, J. J., \& Jhonson, R. (1990). Measurement and Evaluation for Physical Education. USA: Brown Company.

Magil, R. A. (2004). Motor Learning, Concepts and Applications. USA: Brown Company.

Nazir, M. (1998). Metode Penelitian. Penerbit Graha Indonesia, Jakarta.

Preiss, S. M. (1992). Table Tennis, The Sport. USA: Wm.C. Brown.

Schmidt, R. A. (1991). Motor Control and learning. Human Kinetics, USA.

Simpson, P. (2007). Teknik Bermain Ping Pong. Bandung: Pioner Jaya.

Verducci, F. (1980). Measurement Concepts in Physical Education. USA, Mosby Company.

William, J. M. (1994). Applied sport psychology: Personal growth to peak performance. USA, Mayfield.

\section{Copyrights}

Copyright for this article is retained by the author(s), with first publication rights granted to the journal.

This is an open-access article distributed under the terms and conditions of the Creative Commons Attribution license (http://creativecommons.org/licenses/by/3.0/). 